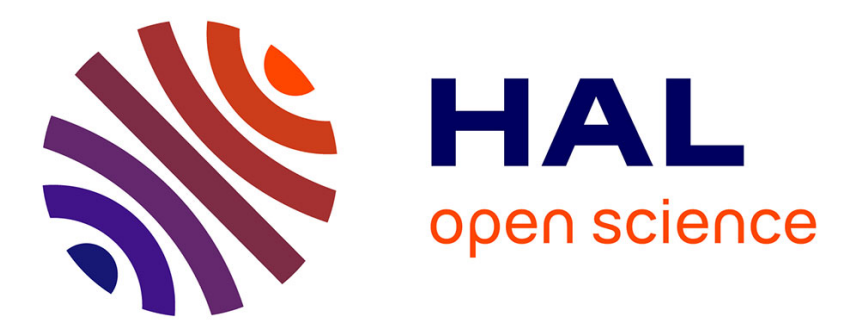

\title{
On numerical implementation of a coupled rate dependent damage-plasticity constitutive model for concrete in application to high-rate dynamics
}

Guillaume Hervé, Fabrice Gatuingt, Adnan Ibrahimbegovic

\section{- To cite this version:}

Guillaume Hervé, Fabrice Gatuingt, Adnan Ibrahimbegovic. On numerical implementation of a coupled rate dependent damage-plasticity constitutive model for concrete in application to high-rate dynamics. Engineering Computations, 2005, 22 (5-6), pp.583-604. hal-00994400

\author{
HAL Id: hal-00994400 \\ https://hal.science/hal-00994400
}

Submitted on 21 May 2014

HAL is a multi-disciplinary open access archive for the deposit and dissemination of scientific research documents, whether they are published or not. The documents may come from teaching and research institutions in France or abroad, or from public or private research centers.
L'archive ouverte pluridisciplinaire HAL, est destinée au dépôt et à la diffusion de documents scientifiques de niveau recherche, publiés ou non, émanant des établissements d'enseignement et de recherche français ou étrangers, des laboratoires publics ou privés. 


\title{
On numerical implementation of a coupled rate dependent damage-plasticity constitutive model for concrete in application to high-rate dynamics
}

\author{
Guillaume Hervé $^{\mathrm{a}}$, Fabrice Gatuingt ${ }^{\mathrm{a}}$, Adnan Ibrahimbegovic ${ }^{\mathrm{a}}$ \\ ${ }^{a}$ Ecole Normale Supérieure de Cachan \\ LMT Cachan \\ 61, avenue du Président Wilson, 94235 Cachan, France \\ e-mail: herve@lmt.ens-cachan.fr, fax:+33(0) 147402240
}

\begin{abstract}
In this work we consider numerical implementation of the modified version of a coupled rate dependent damage-plasticity concrete model first proposed in [8]. We developed an explicit-implicit integration scheme, implemented it in LS-DYNA finite element code, with explicit part dealing with large global problem of equations of motion and implicit part treating local evolution equations. We also provide a detailed consideration of the numerical stability of this kind of scheme for ratedependent damage model. Several numerical tests, both simple ones and a complex problem of the large aircraft impact on a large concrete slab demonstrate the efficiency of the proposed numerical implementation. Comparison between simulations of impact of equivalent aircraft engine missiles and the tests carried out in Sandia laboratory [25] also demonstrates its efficiency.
\end{abstract}

Key words: Concrete constitutive model; damage; plasticity; high-rate dynamic; impact

\section{Introduction}

Transient high rate dynamic behavior of concrete is a very important to take into account for design concrete structures in the case of dynamic loading conditions, such as an impact on the structure. This impact loading can be due to explosion, mind blast or an accidental collision of cars, trains or airplanes with the structure. In particular for structures that involve public safety, they have to be design to resist not only the static loading but also the dynamic loading 
produced extreme conditions. In order to perform a 3D non-linear analysis with a wide variety of damage mechanism in concrete we need a model sufficiently robust and capable of providing a reliable representations for different loading path. But we also need to have a numerical implementation of this model firmly under control in order to ensure a robust computation. In fact, the complexity of any practically interesting model is such that a fully im-

plicit schemes are excluded. In other words, for the numerical simulations of fast transient dynamic, such as an impact on concrete structures, one uses an explicit time integration scheme. The computer program architecture can thus be simplified accordingly, in order to provide a solution for very complex industrial application; with the code as LS-DYNA as one of the most prominent examples, which is also used herein.

The outline of the paper is as follow. In the next section we briefly review the salient feature on the coupled damage plasticity model for high rate dynamics of concrete, adapted to our cases of interest. Then the pertinent details of the chosen scheme for the numerical implementation is presented. In Section 4 we briefly discuss the proposed procedure for model parameters identification. Then the stability of the numerical scheme for a rate dependent damage model is discuss in Section 5. Section 6 provides several illustrative example to show the model performance in representing different inelastic modes of damage in dynamics. Closing remarks and conclusions are given in Section 6 .

\section{Coupled rate dependant damage-plasticity constitutive model for concrete}

This model is first proposed by Gatuingt [8] to simulate explosion in contact or impact of hard projectiles at velocity less than $350 \mathrm{~m} / \mathrm{s}$. For this kind of loading three failure mechanisms have to be described. First one which is observed under the impact is a decrease of the material porosity. This phenomenon is represented with homogenization technics by considering concrete as a matrix (cement paste and aggregates) with pores. To model the penetration of a hard striker introducing a large deviatoric strain, a plastic model based on modified Gurson's yield function (to take into account porosity evolution) is used. The third and final mechanism is supplied to handle the case where the compressive wave can reflect on a free surface producing a traction state of stress which is represented with a damage model.

These mechanical effects are combined in the relationships which relate the stresses to the elastic strains:

$$
\sigma_{i j}=(1-D)\left[K \varepsilon_{k k}^{e} \delta_{i j}+2 G\left(\varepsilon_{i j}^{e}-\frac{1}{3} \varepsilon_{k k}^{e} \delta_{i j}\right)\right]
$$


where the shear $G$ and bulk moduli $K$ of the coupled model are defined by Mori-Tanaka's expressions:

$$
K=\frac{4 K_{M} G_{M}\left(1-f^{*}\right)}{4 G_{M}+3 K_{M} f^{*}} \quad ; \quad G=\frac{G_{M}\left(1-f^{*}\right)}{1+\frac{6 K_{M}+12 G_{M}}{9 K_{M}+8 G_{M}} f^{*}}
$$

with $K_{M}$ and $G_{M}$ respectively the bulk and shear moduli of the matrix material without pores. In the case of a smooth impact (such as impact by cars or airplanes), we can consider that the porosity will not decrease enough under the projectile to induce a variation of the concrete moduli. For the study of these kind of problems we will consider in this paper that $K$ and $G$ remain constant.

The phenomenon of microcracking, in uniaxial tension and compression, is captured with a rate dependent damage model [5]. Accounting for rate effects is necessary in order to represent the type of response one finds in dynamic experiments, mostly dynamic tensile tests [15]). In addition, the added benefit of the rate dependency is to preserve the well-posedness of the equations of motion when strain softening occurs [18], [24]. The extensive program of experiments carried out within the French research network GEO showed that there was a marked dependence between the loading rate and the curve relating the volumetric strain to the hydrostatic stress [7]. The latter is thus captured by implementing a viscoplasticity model. Within the classical framework of small strain cinematics, we use the basic assumption of additive strain decomposition:

$$
\dot{\varepsilon}_{i j}=\dot{\varepsilon}_{i j}^{e}+\dot{\varepsilon}_{i j}^{v p}
$$

where $\dot{\varepsilon}_{i j}$ is the total strain rate, $\dot{\varepsilon}_{i j}^{e}$, the elastic one and $\dot{\varepsilon}_{i j}^{v p}$ the viscoplastic strain rate.

The viscoplastic strain rates are obtained following Perzyna's approach:

$$
\dot{\varepsilon}_{i j}^{v p}=\dot{\lambda} \frac{\partial F_{N T}}{\partial \sigma_{i j}}
$$

The viscoplastic multiplier $\dot{\lambda}$ is defined with the power law which also takes into account the porosity $f^{*}$ :

$$
\dot{\lambda}=\frac{f^{*}}{\left(1-f^{*}\right)}\left\langle\frac{F_{N T}}{m_{v p}}\right\rangle^{n_{v p}}
$$

where $m_{v p}$ and $n_{v p}$ are material parameters. The porosity evolution is controlled by the irreversible volumetric strain only according to:

$$
\mathrm{d} f^{*}=k\left(1-f^{*}\right) f^{*} \mathrm{~d} \varepsilon_{k k}^{p}
$$

where parameter $k$ is introduced in equation (6) in order to be able to calibrate the velocity with which voids are closed. 
In equation above, $F_{N T}$ is the modified Gurson's yield function proposed by Needleman and Tvergaard [17]:

$$
F_{N T}\left(\sigma_{i j}, \sigma_{M}, f^{*}\right):=\frac{3 J_{2}}{\sigma_{M}^{2}}+2 q_{1} f^{*} \cosh \left(q_{2} \frac{I_{1}}{2 \sigma_{M}}\right)-\left(1+\left(q_{3} f^{*}\right)^{2}\right)=0
$$

where $I_{1}=\operatorname{Tr}(\sigma)$, the first invariant of stress tensor, $J_{2}=\|\operatorname{dev}(\sigma)\|$, the second invariant of the deviatoric part, $\sigma_{M}$ is the stress in concrete matrix without voids and $q_{1}, q_{2}, q_{3}$ are scalars parameters. The model of this kind treats the concrete as a porous material. This porosity has a great importance on the material behavior when the hydrostatic stress contribution is not negligible. Indeed, this model improves upon the Drucker-Prager [4] yield surface which is often used for concrete with consequences that the material remains elastic for triaxial compression, which is in contradiction with the compaction experimentally observed [3]. The main interest in the modified Gurson's yield function is to be closed for a hydrostatic state of stress and to provide a kind of CAP model [9], [10] or [11].

The constitutive response in tension and compression is controlled by the damage evolution law governed by a rate dependent model given by :

$$
\dot{D}=\left(\frac{<\tilde{\varepsilon}^{e}-\varepsilon_{D 0}-\frac{1}{a}\left(\frac{D}{1-D}\right)^{(1 / b)}>}{m_{D}}\right)^{n_{D}}
$$

with the damage criterion of Mazars [19]

$$
f=\tilde{\varepsilon}^{e}-\kappa
$$

where $\tilde{\varepsilon}^{e}=\sqrt{\sum_{i}\left(\left\langle\varepsilon_{i}^{e}\right\rangle^{+}\right)^{2}}$ is the elastic equivalent strain for quasi-brittle materials [19]. In Equation (8) above $m_{D}, n_{D}$ are material parameters which control the rate effect, $a, b$ are material parameters which govern the growth of damage in quasistatic tension and compression and $\varepsilon_{D 0}$ is the initial value of damage threshold.

Figure 1 shows the coupled plasticity-damage model response for the hydrostatic stress state for a loading/unloading cycle. We can see that the model captures both strain hardening effect with concrete compaction and the irreversible plastic residual strain upon unloading. 


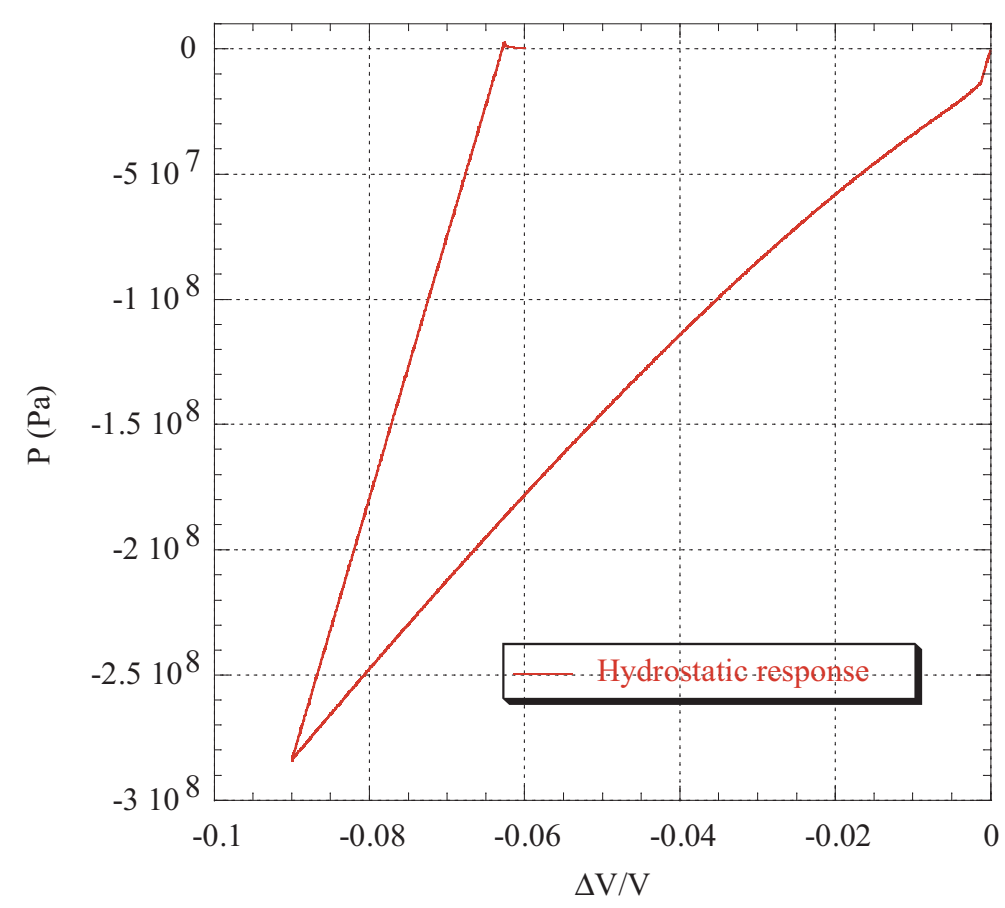

Fig. 1. Hydrostatic response of the model used

\section{Numerical implementation}

Given the complexity of the constitutive relations and the main application domain which pertains to concrete in fast transient dynamics, the model has been implemented in the explicit finite element code LS-DYNA [13]. The objective of the numerical implementation of the model is to be able to calculate the new state of stress at time $t+\Delta t$ knowing the increment of strain $\Delta \varepsilon$ and the state of strain at time $t$. In this computational process, the evolution of the damage and viscoplastic strain are totally decoupled in order to preserve the computational efficiency. We refer to Figure 2 for the flow-chart of the implemented computational procedure, which provides the summary of all different cases.

In a first time, we assume that all the strain increment are elastic and we compute the equivalent elastic strain:

$$
\begin{aligned}
& \varepsilon_{i j}^{e}(t+\Delta t)=\varepsilon_{i j}(t+\Delta t)-\varepsilon_{i j}^{v p}(t) \\
& \tilde{\varepsilon}^{e}(t+\Delta t)=\sqrt{\sum_{i}\left(\left\langle\varepsilon_{i}^{e}(t+\Delta t)\right\rangle^{+}\right)^{2}}
\end{aligned}
$$

Furthermore, we assume that all internal variables remain fixed with their rates $\left(\dot{f}^{*}, \dot{\sigma}_{M}\right.$ and $\left.\dot{D}\right)$ equal to zero, so that we can compute the corresponding stress rate in the elastic predictor: 


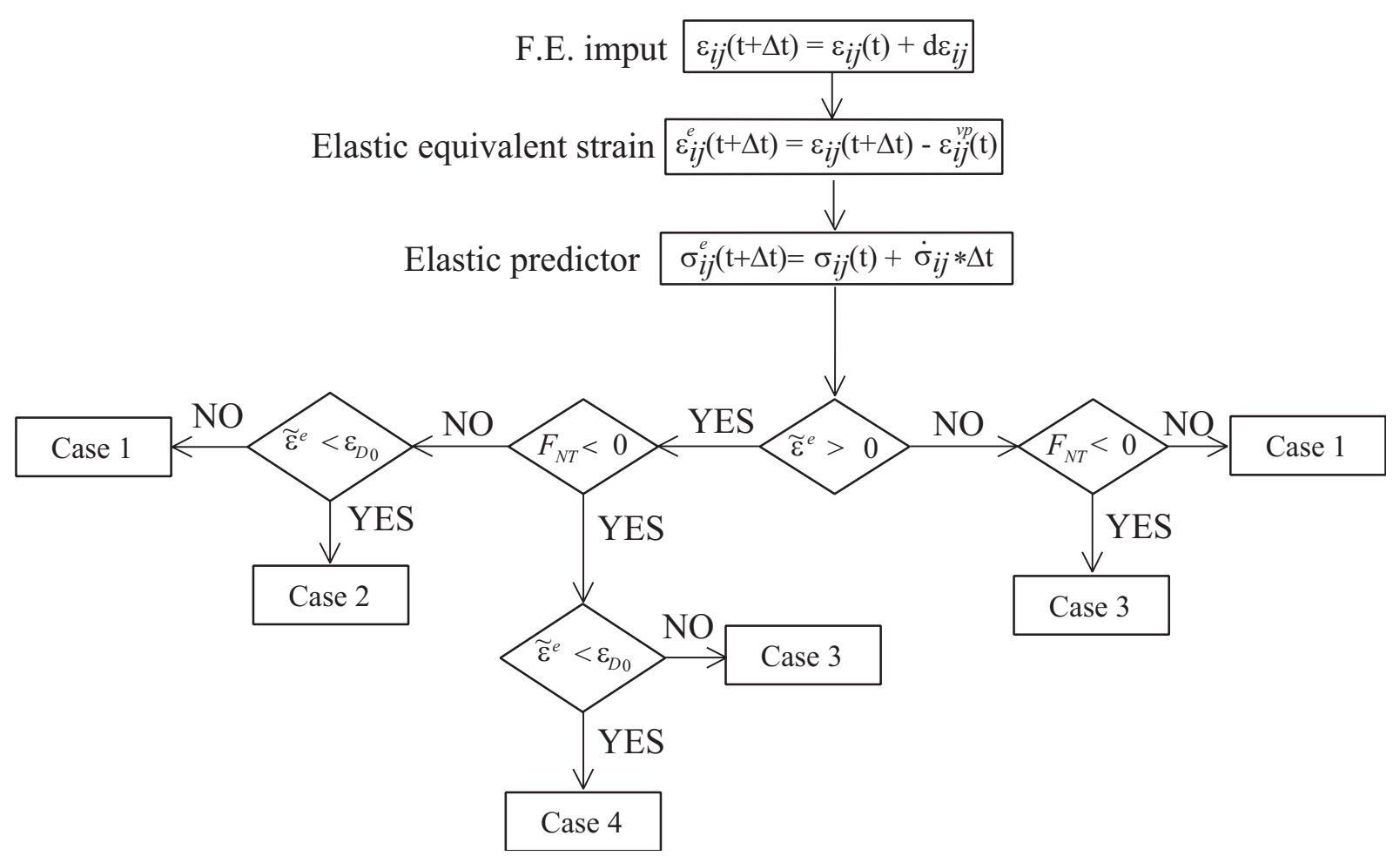

Fig. 2. Numerical integration scheme

$$
\begin{aligned}
& \dot{\varepsilon}_{i j}(t+\Delta t)=\dot{\varepsilon}_{i j}^{e}(t+\Delta t)+\dot{\varepsilon}_{i j}^{v p}(t+\Delta t)=\dot{\varepsilon}_{i j}^{e}(t+\Delta t) \\
& \dot{\sigma}=(1-D(t))\left[K \dot{\varepsilon}_{k k}(t+\Delta t) \delta_{i j}+2 G\left(\dot{\varepsilon}_{i j}(t+\Delta t)-\frac{1}{3} \dot{\varepsilon}_{k k}(t+\Delta t) \delta_{i j}\right)\right] \\
& \dot{\varepsilon}_{i j}^{v p}(t+\Delta t)=0 ; \quad \dot{f}^{*}(t+\Delta t)=0 ; \quad \dot{\sigma}_{M}(t+\Delta t)=0
\end{aligned}
$$

In order to verify if the correction is needed to obtain the real state of stress, we test the positivity of the elastic equivalent strain predicted. If this strain is negative, we deal with a loading path mainly in triaxial compression and the damage variable $D$ will never evolve. We are thus concerned with either the case 1 (elasticity) or with the case 3 (only plasticity) as shown in Figure 2. In case 2 we only have a damage evolution with no plasticity. For the "coupled" case 4, we have evolutions of the damage variable and of the plastic strain. In this case, we first compute the new state of damage and we use it to compute the plastic correction without any subsequent iteration.

For the plastic correction we use the return mapping algorithm [20] for the plastic part of the model assuming that the damage $D$ is known at the state $t+\Delta t$. The latter is computed first from the evolution of the damage during the incremental process, by using an explicit scheme due to the formulation of the damage growth (see equation 8). We can then write: 


$$
\begin{aligned}
& \dot{\varepsilon}_{i j}(t+\Delta t)=\dot{\varepsilon}_{i j}^{e}(t+\Delta t)+\dot{\varepsilon}_{i j}^{v p}(t+\Delta t)=0 \Longrightarrow \dot{\varepsilon}_{i j}^{e}(t+\Delta t)=-\dot{\varepsilon}_{i j}^{v p}(t+\Delta t) \\
& \dot{\sigma}_{i j}=-\left(1-D(t+\Delta t)\left[K \dot{\varepsilon}_{k k}^{v p} \delta_{i j}+2 G\left(\dot{\varepsilon}_{i j}^{v p}-\frac{1}{3} \dot{\varepsilon}_{k k}^{v p} \delta_{i j}\right)\right]\right. \\
& \dot{\varepsilon}_{i j}^{v p}=\dot{\lambda} \frac{\partial F_{N T}}{\partial \sigma_{i j}} \\
& \dot{f}^{*}=k\left(1-f^{*}\right) f^{*} \dot{\varepsilon}_{k k}^{v p}=\dot{\lambda} k\left(1-f^{*}\right) f^{*} \frac{\partial F_{N T}}{\partial \sigma_{k k}} \\
& \dot{\sigma}_{M}=\dot{\lambda} \frac{E_{t}}{\left(1-f^{*}\right) \sigma_{M}} \frac{\partial F_{N T}}{\partial \sigma_{i j}} \sigma_{i j}
\end{aligned}
$$

Substituting equation $(12)_{3}$ into equation $(12)_{2}$ we obtain:

$$
\dot{\sigma_{i j}}=-\dot{\lambda}(1-D(t+\Delta t))\left[K \frac{\partial F_{N T}}{\partial \sigma_{k k}} \delta_{i j}+2 G\left(\frac{\partial F_{N T}}{\partial \sigma_{i j}}-\frac{1}{3} \frac{\partial F_{N T}}{\partial \sigma_{k k}} \delta_{i j}\right)\right]
$$

with $\dot{\lambda}=\frac{f^{*}}{\left(1-f^{*}\right)} \frac{F_{N T}}{m_{v p}}$ (see equation $\left.(2)\right)$ for linear viscoplasticity $\left(n_{v p}=1\right)$ and where plastic loading $\left(F_{N T}>0\right)$ is implicitly assumed.

The rate of change of the yield function during the relaxation process can be written as follows (see Figure 3):

$$
\dot{F_{N T}}=\frac{\partial F_{N T}}{\partial \sigma_{i j}}: \dot{\sigma_{i j}}+\frac{\partial F_{N T}}{\partial f^{*}} \cdot \dot{f}^{*}+\frac{\partial F_{N T}}{\partial \sigma_{M}} \cdot \dot{\sigma}_{M}
$$

Substituting $\dot{\sigma_{i j}}, \dot{f}^{*}$ and $\dot{\sigma}_{M}$ with their evolutions in equation (12), defined as a function of the plastic multiplier $\dot{\lambda}$, we obtain an ordinary differential equation to solve:

$$
\begin{aligned}
\dot{F_{N T}}= & -\frac{F_{N T}}{m_{v p}}\left(\frac{f^{*}}{1-f^{*}}\right)\left\{\frac{\partial F_{N T}}{\partial \sigma_{i j}}:(1-D)\left[K \frac{\partial F_{N T}}{\partial \sigma_{k k}} \delta_{i j}+2 G\left(\frac{\partial F_{N T}}{\partial \sigma_{i j}}-\frac{1}{3} \frac{\partial F_{N T}}{\partial \sigma_{k k}} \delta_{i j}\right)\right]\right. \\
& +\frac{\partial F_{N T}}{\partial f^{*}} \cdot k\left(1-f^{*}\right) f^{*} \frac{\partial F_{N T}}{\partial \sigma_{k k}} \\
& \left.+\frac{\partial F_{N T}}{\partial \sigma_{M}} \cdot \frac{E_{t}}{\left(1-f^{*}\right) \sigma_{M}} \frac{\partial F_{N T}}{\partial \sigma_{i j}} \sigma_{i j}\right\}
\end{aligned}
$$

This kind of problem has been solved by Ortiz and Simo [20] introducing the 


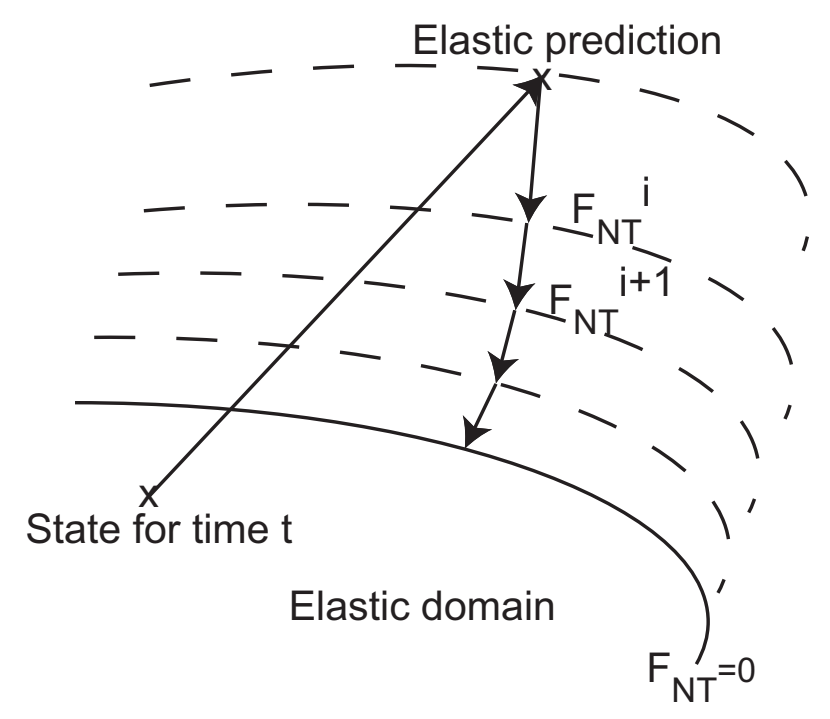

Fig. 3. Principle of the return mapping

instantaneous relaxation time $\bar{t}$ :

$$
\begin{aligned}
\bar{t}= & m_{v p}\left(\frac{1-f^{*}}{f^{*}}\right) /\left\{\frac{\partial F_{N T}}{\partial \sigma}:(1-D)\left[K \frac{\partial F_{N T}}{\partial \sigma_{k k}} \delta_{i j}+2 G\left(\frac{\partial F_{N T}}{\partial \sigma_{i j}}-\frac{1}{3} \frac{\partial F_{N T}}{\partial \sigma_{k k}} \delta_{i j}\right)\right]\right. \\
& +\frac{\partial F_{N T}}{\partial f^{*}} \cdot k\left(1-f^{*}\right) f^{*} \frac{\partial F_{N T}}{\partial \sigma_{k k}} \\
& \left.+\frac{\partial F_{N T}}{\partial \sigma_{M}} \cdot \frac{E_{t}}{\left(1-f^{*}\right) \sigma_{M}} \frac{\partial F_{N T}}{\partial \sigma_{i j}} \sigma_{i j}\right\}
\end{aligned}
$$

equation (15) reduces to :

$$
\dot{F_{N T}}=-\frac{F_{N T}}{\bar{t}} \Longrightarrow \ln \left(F_{N T}\right)=\frac{-t}{\bar{t}}
$$

The following algorithm is then applied: the elastic predictor is computed. The return path can then reach a suitably updated yield surface by means of a sequence of straight segment $\Delta^{i} t$ (see figure 3) which is the instantaneous relaxation time of the linear differential equation. 


$$
\begin{aligned}
\Delta^{i} t= & m_{v p}\left(\frac{1-f^{*}\left(t^{i}\right)}{f^{*}\left(t^{i}\right)}\right) /\left\{\frac{\partial F_{N T^{i}}{ }^{i}}{\partial \sigma_{i j}}:(1-D)\left[K \frac{\partial F_{N T}^{i}}{\partial \sigma_{k k}} \delta_{i j}+2 G\left(\frac{\partial F_{N T}^{i}}{\partial \sigma_{i j}}-\frac{1}{3} \frac{\partial F_{N T}^{i}}{\partial \sigma_{k k}} \delta_{i j}\right)\right]\right. \\
& -\frac{\partial F_{N T^{i}}}{\partial f^{*}} \bullet k\left(1-f^{*}\left(t^{i}\right)\right) f^{*}\left(t^{i}\right) \frac{\partial F_{N T^{i}}}{\partial \sigma_{k k}} \\
& \left.-\frac{\partial F_{N T^{i}}}{\partial \sigma_{M}} \bullet \frac{E_{t}\left(t^{i}\right)}{\left(1-f^{*}\left(t^{i}\right)\right) \sigma_{M}\left(t^{i}\right)} \frac{\partial F_{N T^{i}}}{\partial \sigma_{i j}}: \sigma_{i j}\left(t^{i}\right)\right\}
\end{aligned}
$$

To update the variable $\sigma_{i j}, f^{*}$ and $\sigma_{M}$ during the return mapping iterative process, we use:

$$
\begin{aligned}
& \sigma_{i j}\left(t^{i+1}\right)=\sigma_{i j}\left(t^{i}\right)+\dot{\sigma}_{i j}\left(t^{i}\right) \Delta^{i} t \\
& \sigma_{M}\left(t^{i+1}\right)=\sigma_{M}\left(t^{i}\right)+\dot{\sigma}_{M}\left(t^{i}\right) \Delta^{i} t \\
& f^{*}\left(t^{i+1}\right)=f^{*}\left(t^{i}\right)+\dot{f}^{*}\left(t^{i}\right) \Delta^{i} t
\end{aligned}
$$

We can thus compute $F_{N T}^{i+1}$ as well as the new values of the internal variables. The total relaxation time is obtained with the following equation:

$$
t^{i+1}=t^{i}+\Delta^{i} t \cdot \log \frac{F_{N T}^{i}}{F_{N T}^{i+1}}
$$

We obtain the exact plastic correction for $F_{N T}=0$ which is obtained when the total relaxing time is equal to the real time increment $\Delta t[20]$.

During this internal variable computation and in particular for the elastic prediction, we can obtain numerical problem to compute the modified Gurson's yield function (see eq. (7)). This is due to the high numerical values obtained with the cosh function when the term $\frac{q_{2} I_{1}}{2 \sigma_{M}}$ becomes large enough. This phenomenon is represented in Figure 4. We follow Mahnken [16] who proposed to modify the expression of the hyperbolic cosine with the power series development around a critical point. We choose for critical value $\frac{q_{2} I_{1}}{2 \sigma_{M}}=X_{c}=30$ and we obtain the expression:

$$
\begin{aligned}
& \left|\frac{q_{2} I_{1}}{2 \sigma_{M}}\right| \leq X_{c}: F_{N T}\left[\cosh \left(\frac{q_{2} I_{1}}{2 \sigma_{M}}\right)\right] \\
& \left|\frac{q_{2} I_{1}}{2 \sigma_{M}}\right|>X_{c}: F_{N T}\left[\cosh \left(X_{c}\right)+\sinh \left(X_{c}\right)\left(\frac{q_{2} I_{1}}{2 \sigma_{M}}-X_{c}\right)+\frac{1}{2} \cosh \left(X_{c}\right)\left(\frac{q_{2} I_{1}}{2 \sigma_{M}}-X_{c}\right)^{2}\right]
\end{aligned}
$$

This method ensures continuity under the critical point and limits the growth up of this term when $X>X_{c}$. 


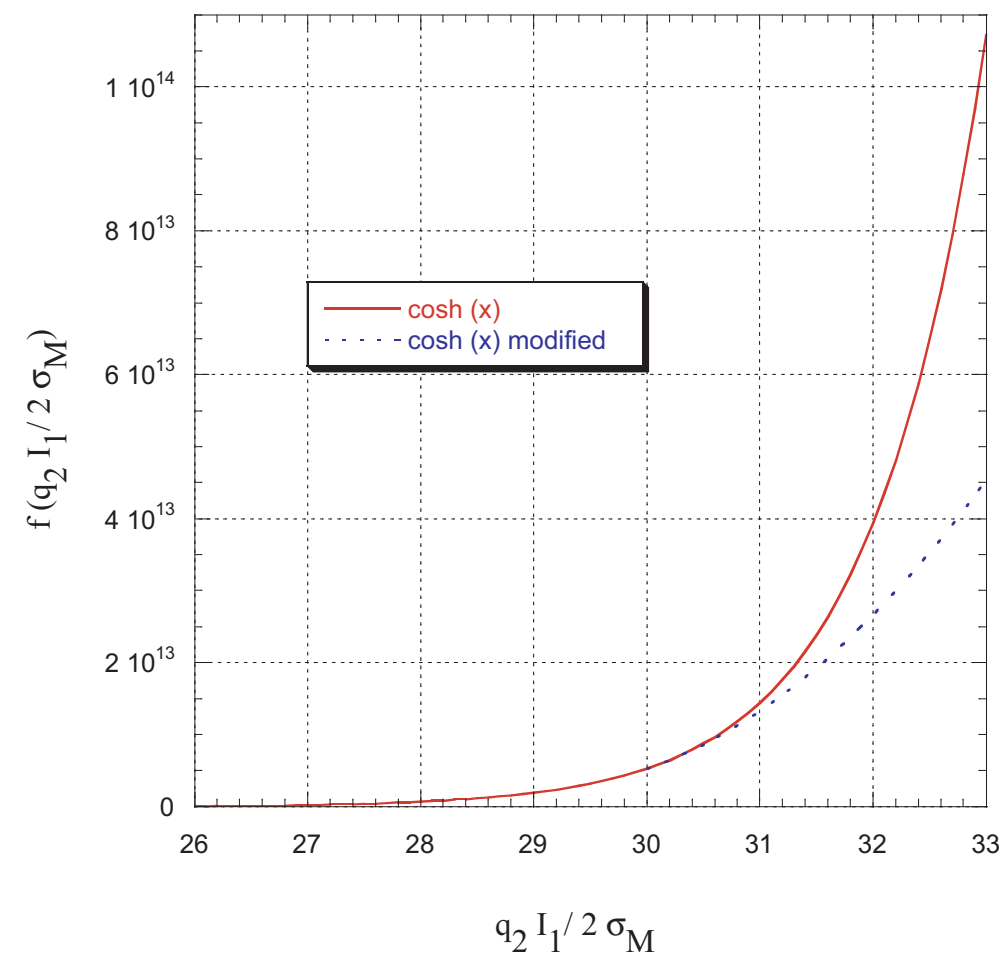

Fig. 4. Modification of the cosh function to prevent numerical overflow

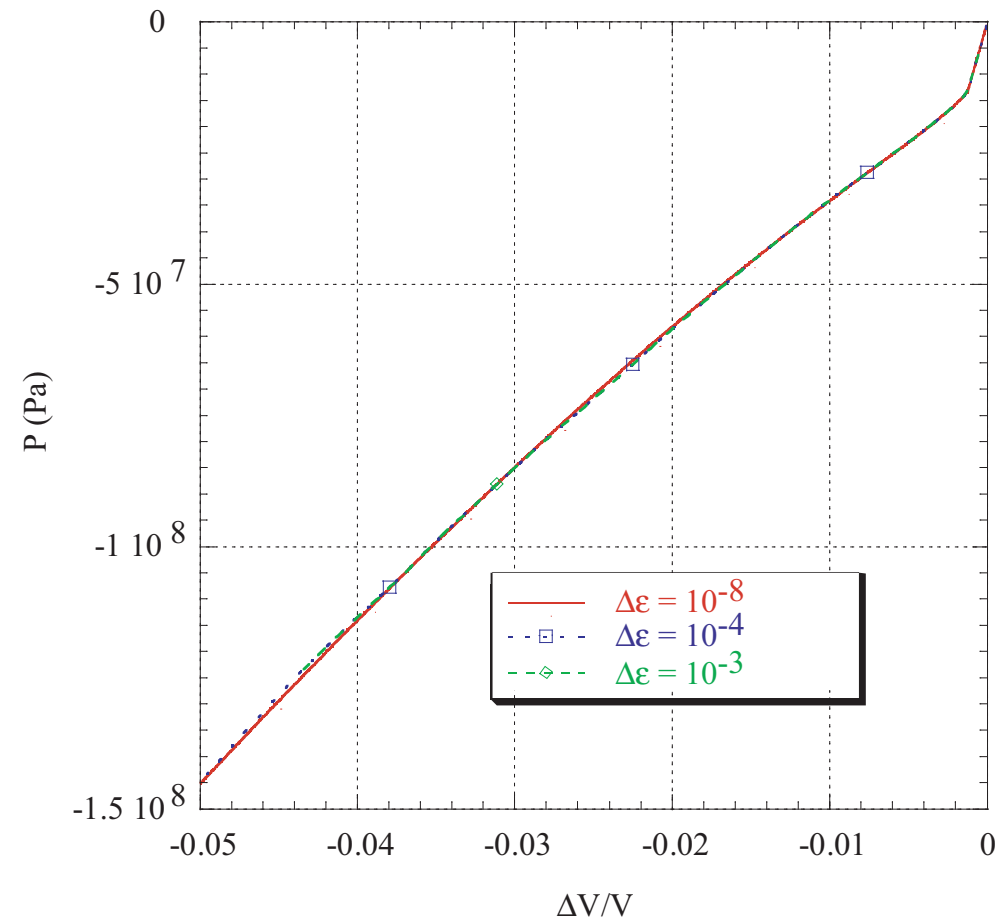

Fig. 5. Hydrostatic response for different strain increment 
Figure 5 shows the response of the model for a hydrostatic compression (where only the plastic criterion is activated) for different strain increment but with the same strain rate. We can notice that the model response is now totally independent of the strain increment. This is due to the implicit integration scheme used for the plasticity.

\section{Parameters identification}

The main goal of this section is to give a systematic procedure in order to calibrate and choose the model parameters. We saw in Section 2 that the constitutive equations are governing with two inelastic threshold functions. The first one is based on Mazars's work and concerns the damage evolution. The second one is the modified Gurson's yield function for the evolution of the plastic strain. It is important to note that, the Mazars's threshold function is activated in traction before the Gurson's yield function, means that only the damage constitutive law is used see Figure 6 . The representation of the yield functions was generated with MatSGen software developed at LMT-Cachan by François [6]. So if we want to calibrate the model damage parameters we have to perform a traction test in statics and in dynamics. In addition, for a triaxial compression load path, only the Gurson's yield function is activated which means that we will use only the viscoplastic constitutive law. To calibrate the model parameters for the viscoplastic strain evolution, we have to perform the hydrostatic compression test in statics and in dynamics. On the other hand, if we are in a load path in simple compression with low confinement, we activate the two thresholds and we will have a coupled response of the constitutive equation. Nevertheless, if we choose appropriate parameters, we can obtain a simple compression depending only on the damage law which will permit to calibrate the damage parameters in compression.

In table 1 we present a summary of the parameter values for MB50.

\section{Stability of the numerical implementation}

\subsection{Rate dependant damage model}

An homogeneous material element at a macroscopic point of view deforms in a homogeneous manner if a homogeneous stress is applied at its boundaries. But when the strain becomes larger, due to the loading for example, concentration can occur in one element which lead to localization of strain over more or less extended area and the deformation of the considered element ceased to be homogeneous. 


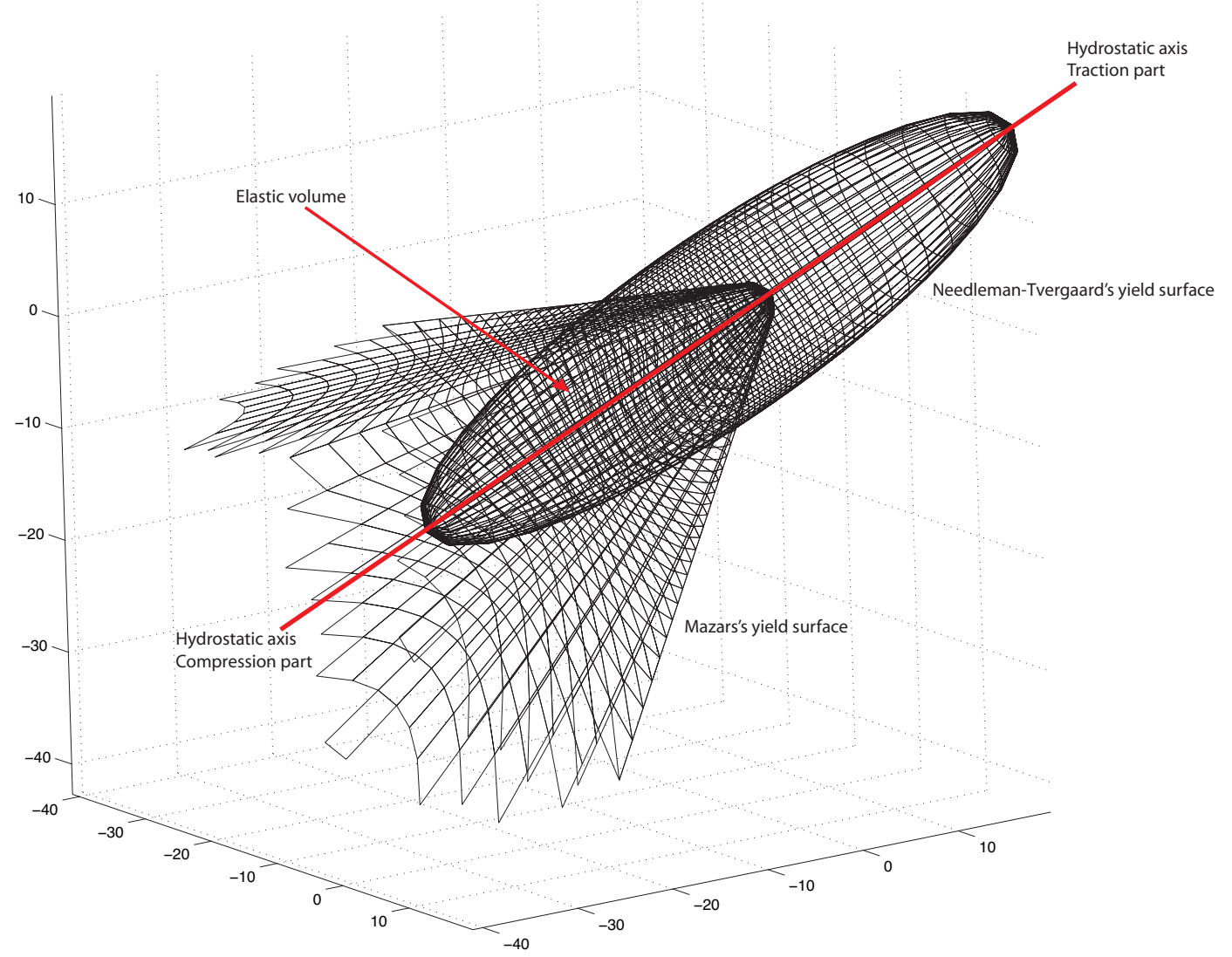

Fig. 6. Needleman-Tvergaard and Mazars yield function in stress space

Table 1

Model parameters for MB50

\begin{tabular}{ccc|ccc}
\hline Plasticity par. & Values & Units & Damage par. & Values & Unity \\
\hline $\mathrm{E}_{0}$ & $5.510^{10}$ & $\mathrm{~Pa}$ & $\mathrm{E}_{0}$ & $3.510^{10}$ & $\mathrm{~Pa}$ \\
$\nu$ & 0.2 & - & $\nu$ & 0.2 & - \\
$q_{1}$ & 1.5 & - & $\epsilon_{D_{0}}$ & $1.10^{-4}$ & - \\
$q_{2}$ & 0.8 & - & $a_{t}$ & 20000 & - \\
$q_{3}$ & 1 & - & $b_{t}$ & 1.6 & - \\
$\sigma_{M_{0}}$ & 60 & $\mathrm{MPa}$ & $n_{D_{t}}$ & 5 & - \\
$n$ & 15 & - & $m_{D_{t}}$ & $0.510^{-4}$ & - \\
$k$ & 45 & - & $a_{c}$ & 3000 & - \\
$m_{v p}$ & $1.110^{-2}$ & - & $n_{D_{c}}$ & 20 & - \\
$n_{v p}$ & 1 & - & $m_{D_{c}}$ & $0.510^{-3}$ & -
\end{tabular}


A good way for describing localization in terms of continuum theory is the strain rate discontinuity $[23,21,22]$. The localization implies a non uniqueness in the incremental response of a homogeneous, homogeneously strained body and also implies a vanishing speed of acceleration waves $[12,14]$.

The equation of the damage model is:

$$
\boldsymbol{\sigma}=(1-D) \boldsymbol{E} \boldsymbol{\varepsilon}
$$

with the evolution law of the damage governed by a rate dependent model (see equation (8)) considering $n_{D}=1$. This is an evolution problem which is solved by a time integration scheme. This latter provides a discretized solution of this evolution problem, which can be written as :

$$
\begin{aligned}
& \operatorname{div} \boldsymbol{\sigma}_{n+1}=0 \\
& \boldsymbol{\sigma}_{n+1}=\left(1-D_{n+1}\right) \boldsymbol{E} \boldsymbol{\varepsilon}_{n+1}=G\left(\boldsymbol{\varepsilon}_{n+1}, D_{n+1}\right) \\
& \Delta D=D_{n+1}-D_{n}=\Delta t \dot{D}_{n+1}=F\left(\boldsymbol{\varepsilon}_{n+1}, D_{n+1}\right)
\end{aligned}
$$

This is a non-linear problem which can be solved by the Newton scheme. We have to ensure that this remains a well-posed problem by verifying the positiveness of the consistent tangent operator.

Therefore, we linearize the non-linear evolution laws:

$$
\begin{aligned}
& \delta \boldsymbol{\sigma}_{n+1}=\frac{\partial G}{\partial \varepsilon_{n+1}}: \delta \varepsilon_{n+1}+\frac{\partial G}{\partial D_{n+1}} \delta D_{n+1} \\
& \delta D_{n+1}=\frac{\partial F}{\partial \varepsilon_{n+1}}: \delta \varepsilon_{n+1}+\frac{\partial F}{\partial D_{n+1}} \delta D_{n+1}
\end{aligned}
$$

With the equation $(24)_{2}$ we have:

$$
\delta D_{n+1}=\frac{\frac{\partial F}{\partial \varepsilon_{n+1}}: \delta \varepsilon_{n+1}}{1-\frac{\partial F}{\partial D_{n+1}}}
$$

Using this expression of $\delta D_{n+1}$ in equation $(24)_{1}$ we can write:

$$
\delta \boldsymbol{\sigma}_{n+1}=H \quad: \delta \boldsymbol{\varepsilon}_{n+1}
$$

with

$$
H=\frac{\partial G}{\partial \varepsilon_{n+1}}+\frac{\frac{\partial G}{\partial D_{n+1}} \otimes \frac{\partial F}{\partial \varepsilon_{n+1}}}{1-\frac{\partial F}{\partial D_{n+1}}}
$$


the tangent modulus of the non-linear evolution law. In our case, we have:

$$
\begin{aligned}
\frac{\partial G}{\partial \boldsymbol{\varepsilon}_{n+1}} & =\left(1-D_{n+1}\right) \boldsymbol{E} \\
\frac{\partial G}{\partial D_{n+1}} & =-\boldsymbol{E} \boldsymbol{\varepsilon}_{n+1} \\
\frac{\partial F}{\partial \boldsymbol{\varepsilon}_{n+1}} & =\frac{\Delta t}{m_{D}} \frac{<\boldsymbol{\varepsilon}_{n+1}>_{+}}{\tilde{\varepsilon}_{n+1}} \\
\frac{\partial F}{\partial D_{n+1}} & =-\frac{\Delta t}{m_{D}} \cdot \frac{\frac{1}{a}\left(\frac{D_{n+1}}{1-D_{n+1}}\right)^{(1 / b)}}{b D_{n+1}\left(1-D_{n+1}\right)}=-\alpha \frac{\Delta t}{m_{D}}
\end{aligned}
$$

Which leads to :

$$
H=\left(1-D_{n+1}\right) \boldsymbol{E}+\frac{-\boldsymbol{E} \boldsymbol{\varepsilon}_{n+1} \otimes \frac{\Delta t}{m_{D}} \frac{<\boldsymbol{\varepsilon}_{n+1}>_{+}}{\tilde{\varepsilon}_{n+1}}}{1+\alpha \frac{\Delta t}{m_{D}}}
$$

In order to solve the problem, we have to verify the equilibrium for the linearized problem:

$$
\operatorname{div} \delta \boldsymbol{\sigma}_{n+1}=0
$$

which is a well-posed problem under the condition:

$$
\operatorname{det} \mathrm{nHn}=0
$$

With the tangent modulus obtained in equation (29) we obtain from the last expression :

$$
\operatorname{det}\left[\left(1-D_{n+1}\right) \mathrm{n} \boldsymbol{E} \mathrm{n}-\frac{\Delta t}{m_{D} \cdot \tilde{\varepsilon}_{n+1} \cdot\left(1+\alpha \frac{\Delta t}{m_{D}}\right)} \mathrm{n}\left(\boldsymbol{E} \boldsymbol{\varepsilon}_{n+1} \otimes<\boldsymbol{\varepsilon}_{n+1}>_{+}\right) \mathrm{n}\right]=0
$$

this is verified for [1]:

$$
\frac{m_{D} \cdot \tilde{\varepsilon}_{n+1} \cdot\left(1+\alpha \frac{\Delta t}{m_{D}}\right)}{\Delta t}=\left(<\boldsymbol{\varepsilon}_{n+1}>_{+} \mathrm{n}\right)\left\{\mathrm{n} \boldsymbol{E n}\left(1-D_{n+1}\right)\right\}^{-1}\left(\boldsymbol{E} \boldsymbol{\varepsilon}_{n+1}\right)
$$

\subsection{Application to $1 D$ bar in traction}

For a $1 \mathrm{D}$ bar in traction we can obtain a simple form of the tangent modulus:

$$
H=\left(1-D_{n+1}\right) E-E \varepsilon_{n+1} \frac{\Delta t / m_{D}}{1+\alpha \frac{\Delta t}{m_{D}}}
$$




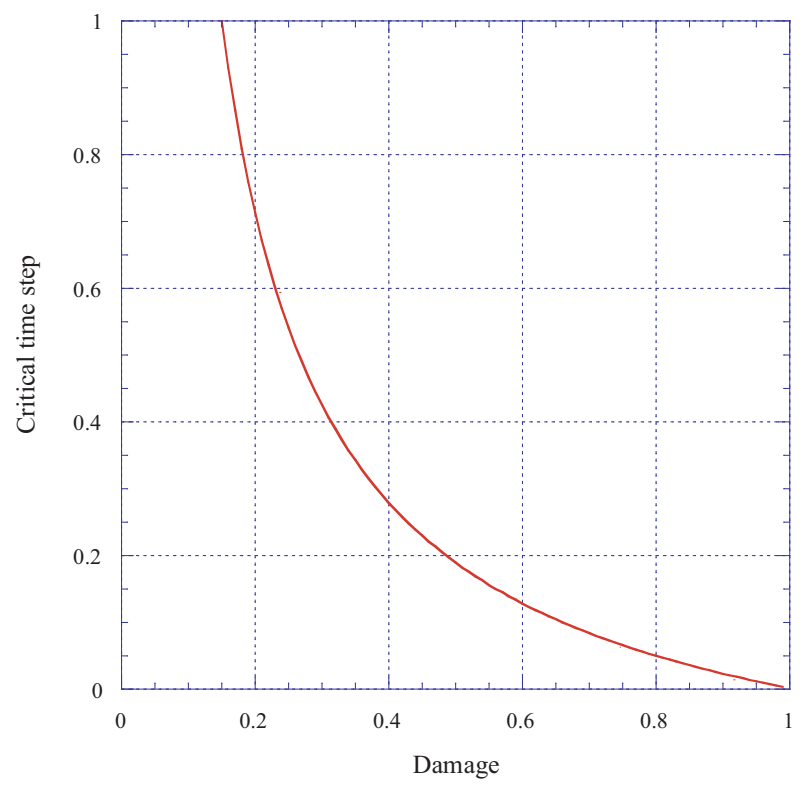

Fig. 7. Critical time step versus damage

For this simple case, the stability condition is $H=0$. With this condition, we can obtain a stability time step $\Delta t$ :

$$
\Delta t=\frac{m_{d}}{\varepsilon_{n+1} /\left(1-D_{n+1}\right)-\alpha}
$$

Figure 7 shows the reduction of the critical time step with the damage increase. This curve has been obtain for model parameters identify for concrete MB50, with the values of parameters given in table 1 . We can observe that for these values, the critical time step is big enough to ensure stability of the numerical scheme even at the end of the damage evolution.

\section{Numerical simulations}

\subsection{Patch Test}

In order to see if the model was implemented correctly in the FE code LSDYNA, we decided to test two different meshes (one regular and one distorted see Figure 8), under a homogeneous stress field - the classical path test (see [27] carried out in dynamics.

First we carried out traction tests on a regular mesh cube and a distorted mesh one in order to check if the damage phenomena exhibit mesh dependency, see 


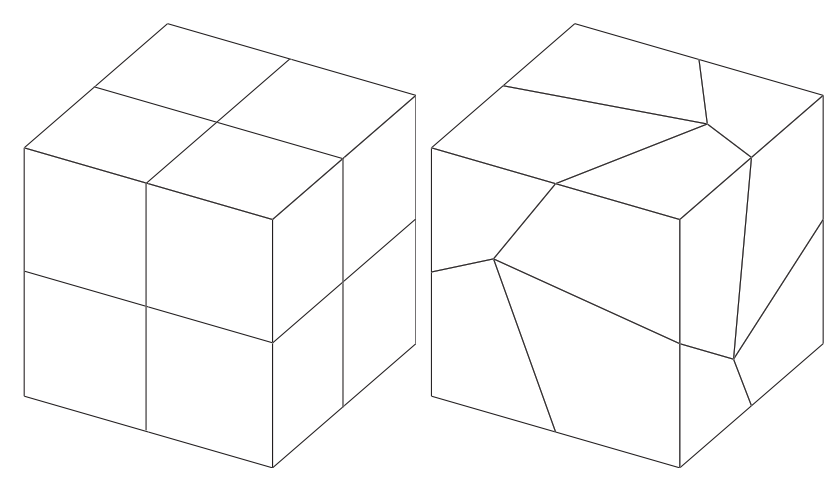

Fig. 8. Regular and distorted meshes used for the patch test
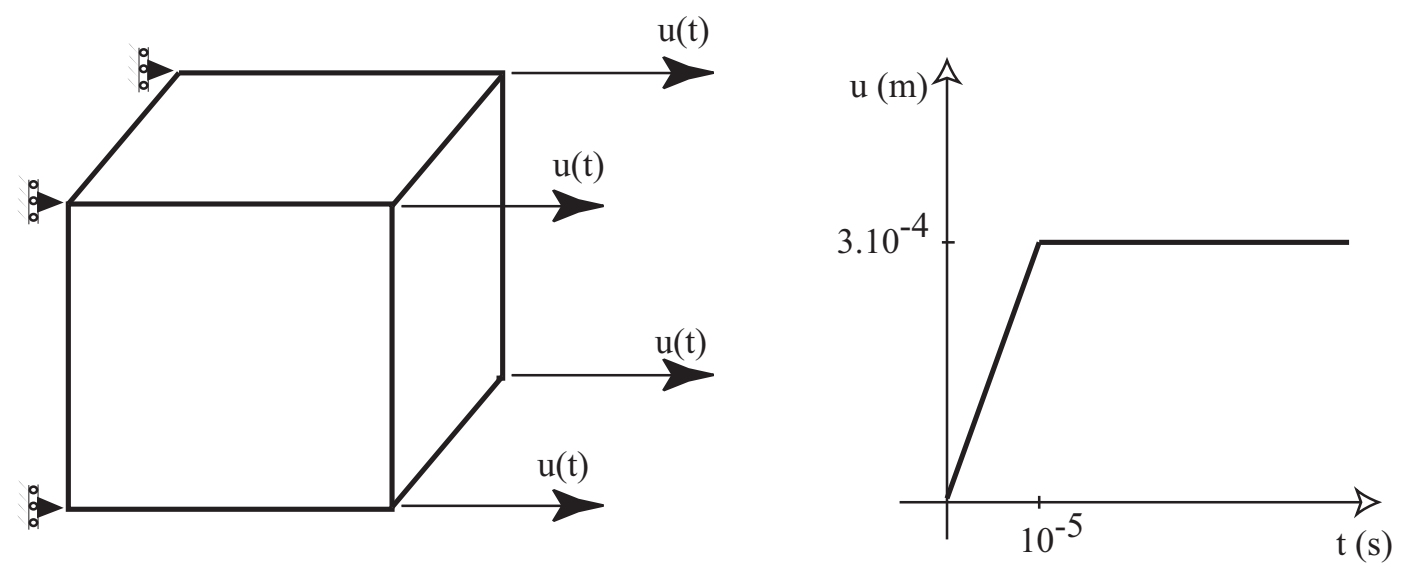

Fig. 9. Patch test in traction

Figure 9.

The stress vs strain diagram clearly indicates no mesh dependency as shown in Figure 10, with two curves which remain in very good accordance.

Then we carried out the same kind of tests for an hydrostatic state of stress as illustrated in Figure 11, with the same purpose to verify the good accordance of the model response for different meshes. Figure 12 showing the hydrostatic pressure vs voluminal strain curves for regular and distorted mesh indeed confirms good accordance in both cases.

\subsection{Reinforced concrete slab}

Another test of the model capabilities was to carry out a large scale computation. As it would be dedicated to simulations of soft impact phenomena and especially aircraft impact, we carried out the computation of impact between 747 class Boeing like aircraft and a reinforced concrete slab.

The slab was a parallelepiped of 80 by 80 meters large and 80 centimeters 


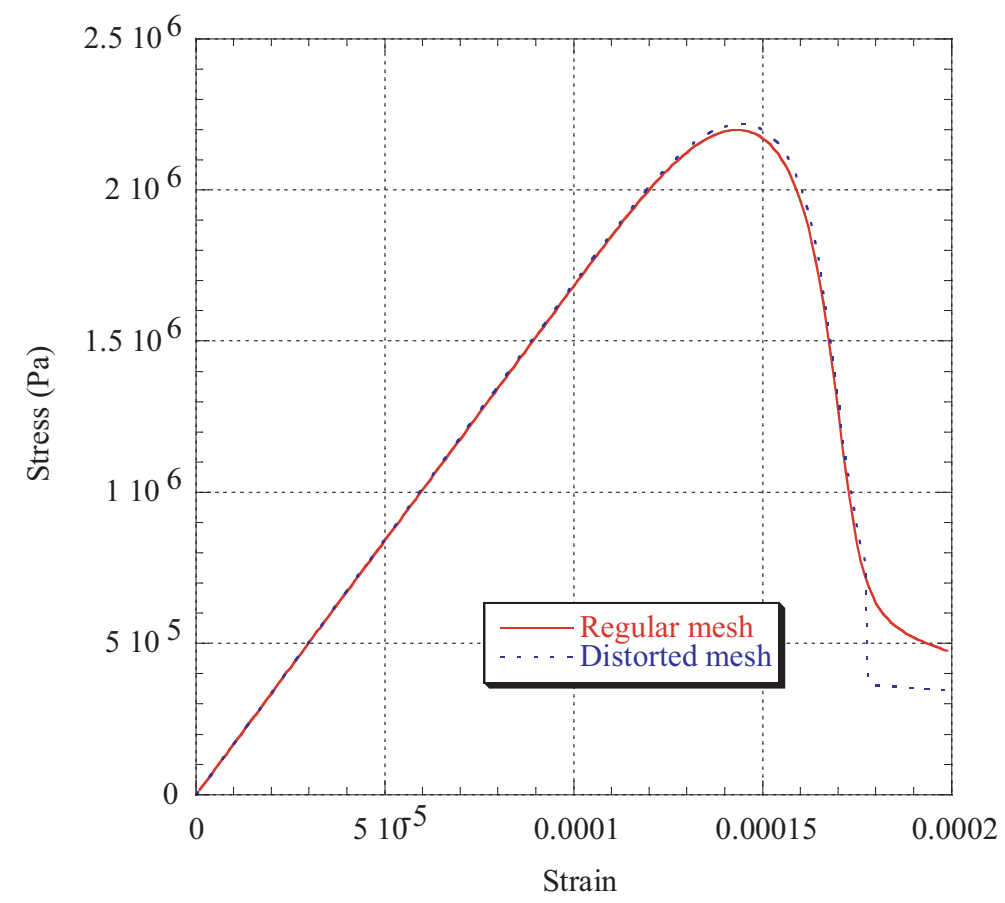

Fig. 10. Traction response for the two different meshes

thick. The concrete within was a classical one of 25 Mpa ultimate compressive stress.

The aircraft impacted the slab following a 20 degrees angle, at $252 \mathrm{~m} / \mathrm{s}$ this means $900 \mathrm{kph}$ the ultimate speed of this kind of aircraft in such a configuration, as it is shown in figure 16.

The finite element model of the aircraft was constructed by a mesh of BelytschkoLin-Tsay shell elements, the slab is constituted of under-integrated (one Gauss point) brick elements . The automatic contact surface to surface LS-DYNA option for contact was used in this simulation.

The reinforcement was represented with beams and a perfect contact between concrete and steel bar was assumed, by merging nodes between beams elements and 3D elements. Reinforcement ratio was $0.4 \%$ in each direction.

The results presented in figure 17 show the evolutions of the damage on the impacted face and the opposite one. When damage reaches the maximum value of 1 the concrete is locally fully destroyed. Thus we can conclude in this 


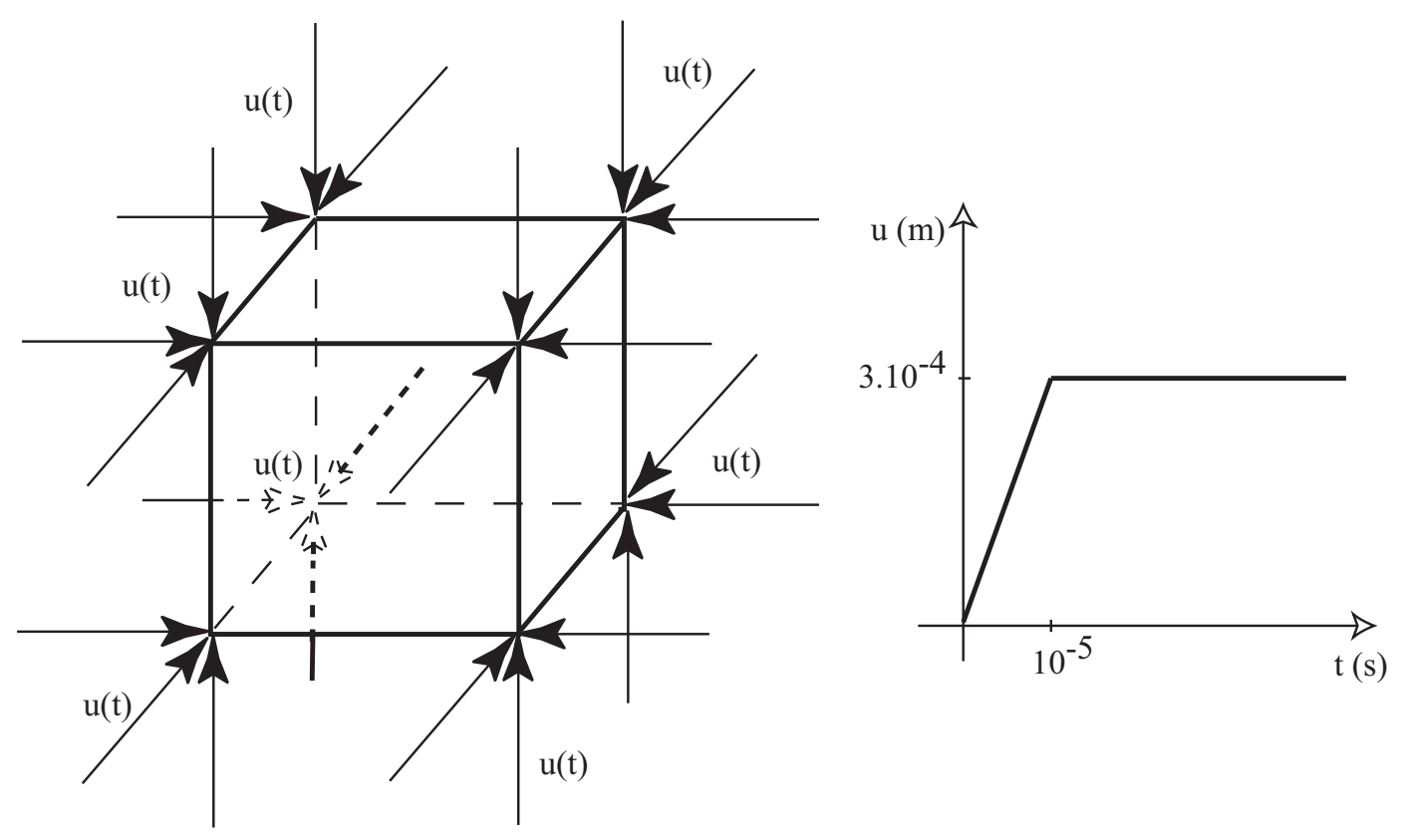

Fig. 11. Patch test in hydrostatic compression

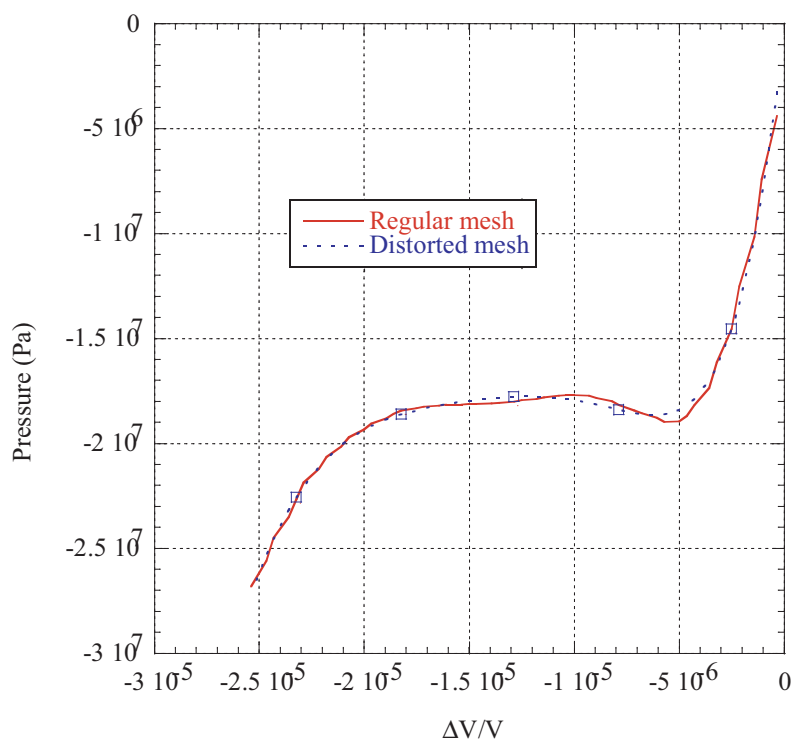

Fig. 12. Hydrostatic response for the two different meshes

case that a huge crater has occurred on the top face of the slab, yet we can assume that the scabbing on the rear face is limited to a $15 \times 15$ meters square area containing nearly 7 disseminated scabbed discs. According to the 0.25 damage value on the half of the opposite face, we can assume that half of rear face is considerably weakened with the presence of several cracks. 


\subsection{Sandia's Laboratory tests simulations}

In order to check the relevance of the constitutive relations we carried out simulations of impact tests performed in Sandia Laboratory by Sugano et al. and presented in [25] and [26]. Following the test program, we simulate impact of $\mathrm{n}$ aircraft engine equivalent missiles, considering several sizes. In particular we carried out simulations of LED, MED and SER missiles which means, respectively, Large size Equivalent and Deformable missile, Medium size Equivalent and Deformable missile and Small size Equivalent Rigid missile. The details for the selected three missiles are presented in Figure 18.

The missiles impacted three slabs, with a particular choice depending on the kind of missiles. The slabs are presented in figure 19, from left to right with the two slabs placed in a box have been used for small size and large size missile tests.

Among several impact tests, carried out by Sugano et al., we chose to simulate impact of those exposed in Table 2 .

In our simulations missiles where represented by using the finite element models constructed with Belytschko-Lin-Tsay shell elements, except for SER missile, whose mesh is built with $3 \mathrm{D}$ elements. The concrete part of the slab was represented with under-integrated 3D elements, the reinforcement was represented with truss-bars. In each case reinforcement ratio was $0.4 \%$ in each direction.

Table 2

Simulated tests characteristics

No. Missile type Missile velocity Slab thickness Reinf. ratio Slab type

\begin{tabular}{cccccc}
\multicolumn{7}{c}{$(\mathrm{m} / \mathrm{s})$} & $(\mathrm{m})$ & \\
\hline S10 & SER & 141 & 0.15 & 0.4 & Small \# 1 \\
S28 & SED & 196 & 0.06 & 0.4 & Small \# 1 \\
L5 & LED & 214 & 1.60 & 0.4 & Large \# 3
\end{tabular}

The qualitative results of numerical simulations, the same as those obtained in the tests, are presented in Table 3; we note that penetration means that the missile penetrated the slab without having gone through it, perforation means that missile went through, scabbing means that the impact generated a scab on the rear face of the slab.

All computations where stopped when the velocity of the missile stopped decreasing, this means when the missile finally got stuck in the concrete, or when concrete did not bring any resistance to its penetration, since the slab was totally damaged. The damage fringes of the simulations at the end of the computations are exposed in Figures 13, 14 and 15, respectively, for impact 
Table 3

Tests results for each impact

\begin{tabular}{cccc}
\hline No. & Perforation & Scabbing & Penetration \\
\hline S10 & No & Yes & Yes \\
S28 & Yes & Yes & Yes \\
L5 & No & Some cracks & Yes
\end{tabular}
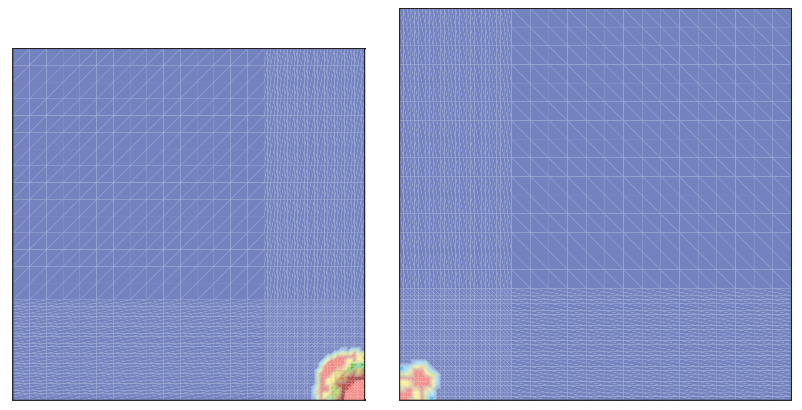

Fig. 13. Simulations of S10 test - Top, bottom and side views
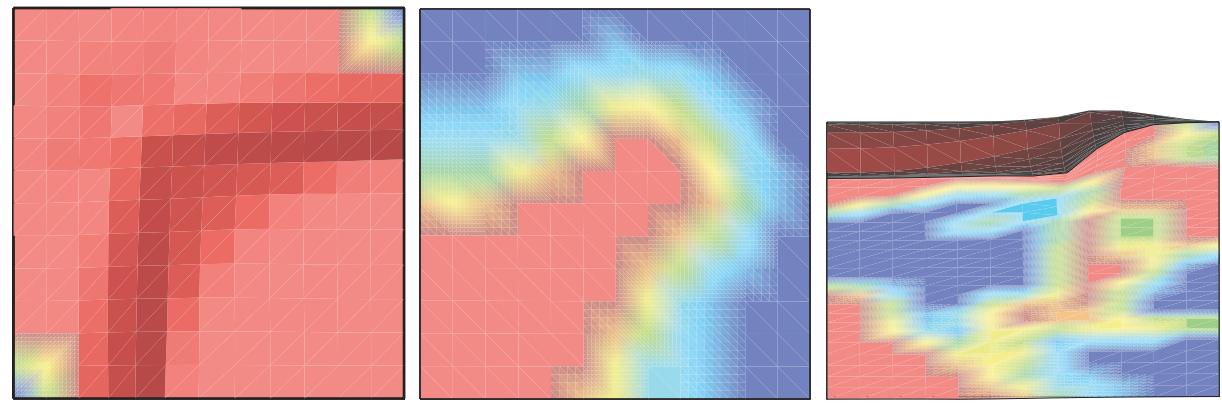

Fig. 14. Simulations of S28 test - Top, bottom and side views

tests S10, S28 and L5. In figure 13, we can observe that the damage is not enough continuous to let the missile goes through, the damage fringe on the rear face exposes that a scabbing is occurring.

In Figure 14 the damage fringe is continuous through the slab thickness under the impacted zone, thus we can conclude that a perforation has occurred and a scabbing too.

In Figure 15, we see that the damage is localized in the impact area, a large undamaged volume separates damage on the rear face and damage on the front face. We can here conclude on a penetration with maybe some cracks or a small scab.

Considering these observations and Table 3, we can conclude that obtained a very good accordance with the tests. The latter also confirms the validation of the constitutive equations that had been developed and also their implementation. 

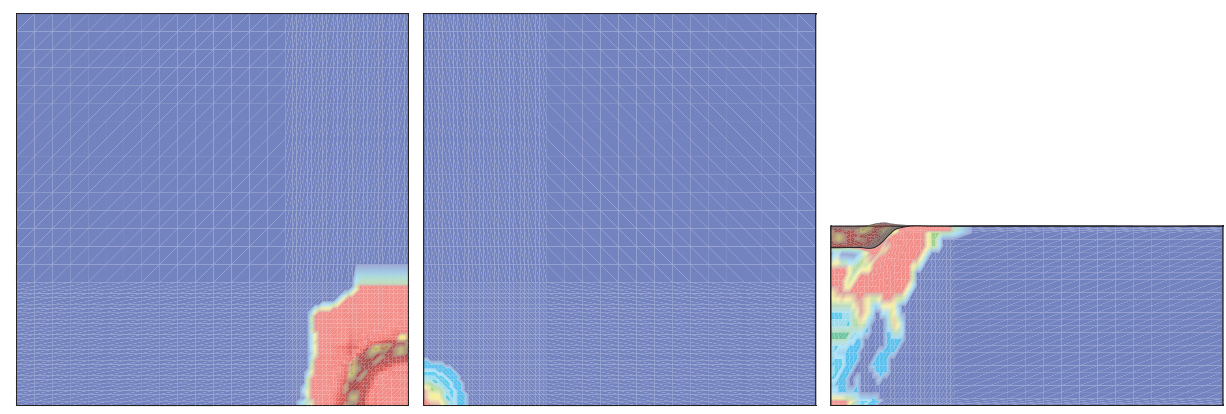

Fig. 15. Simulations of L5 test - Top, bottom and side views
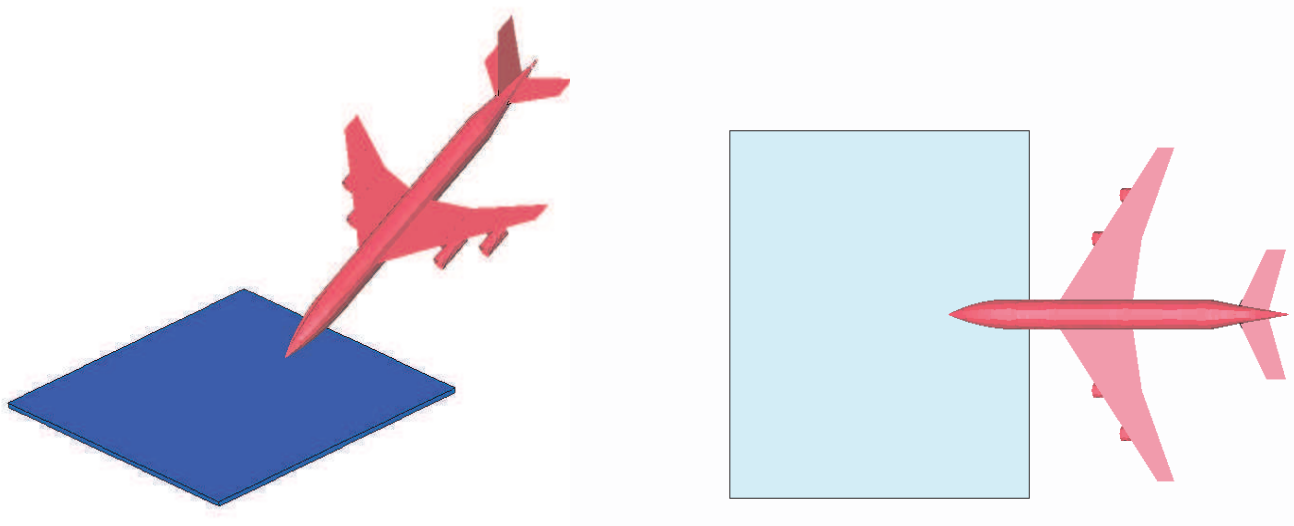

Fig. 16. Configuration of plane and slab before impact

\section{Conclusions}

We have presented a very careful consideration of the numerical implementation aspects for the constitutive model of coupled damage-plasticity, within the framework of explicit-implicit scheme used by computer code LS-DYNA. The proposed integration scheme can be considered as optimal one for the given problem, in which we combine an explicit solution of global equations of motion, with the implicit solution of local evolution equations, which ensures both the computational efficiency and admissible values of stress field during the damage computation. The model is especially suited for representing different damage mechanisms which develop in concrete under high rate loading, both in tension and compression. The former pertains to tension cut-off damage criterion, whereas the latter is represented by the plasticity model with Gurson-like criterion, with a particular feature of accounting for hardening due to concrete compaction. 


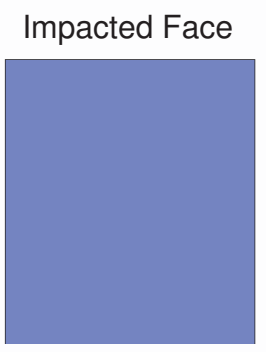

$\mathrm{t}=0 \mathrm{~s}$
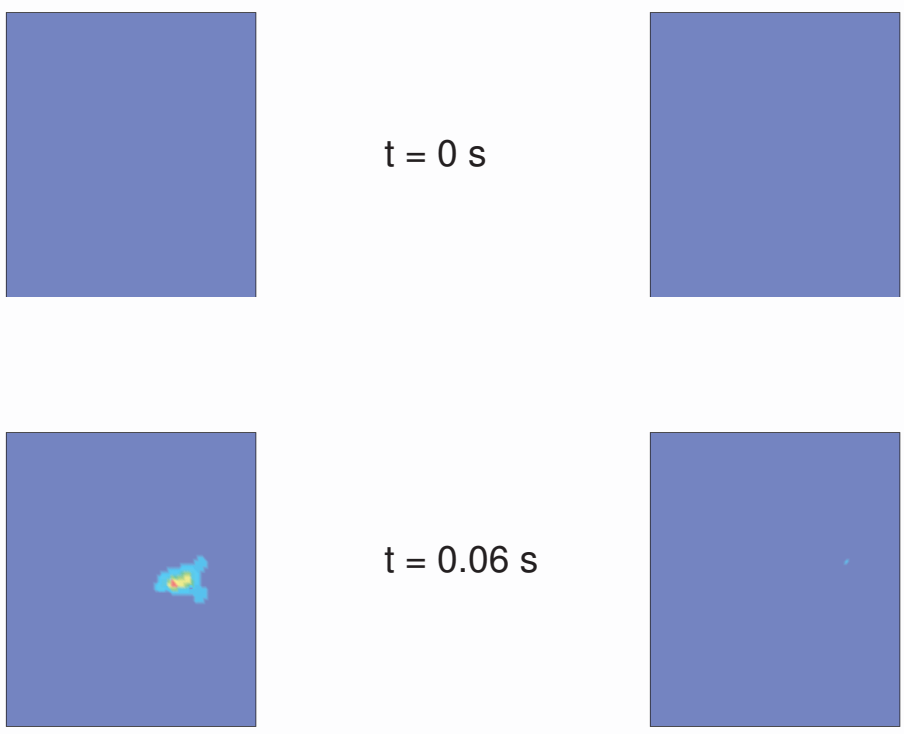

Damage
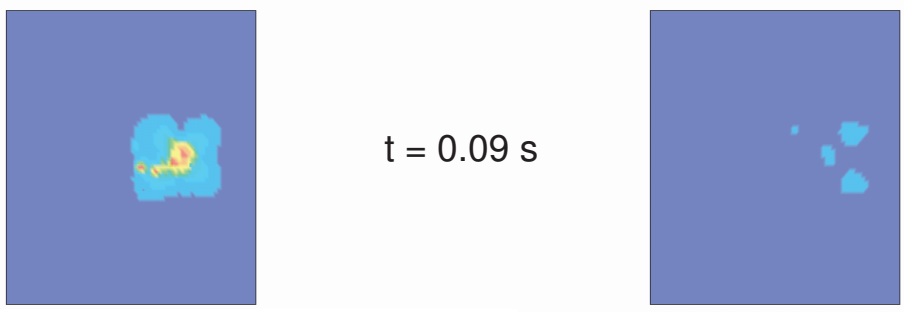

1.

$t=0.09 s$

0.5

$t=0.13 s$

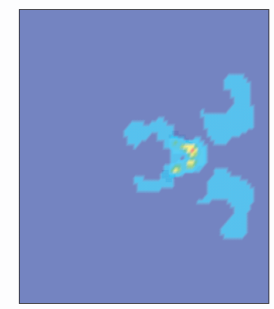

0.

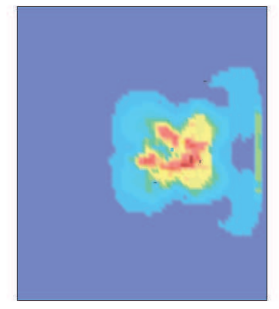

$\mathrm{t}=0.19 \mathrm{~s}$

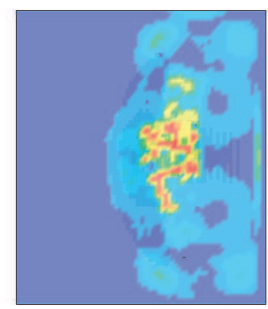

Fig. 17. Damage evolution during the impact 


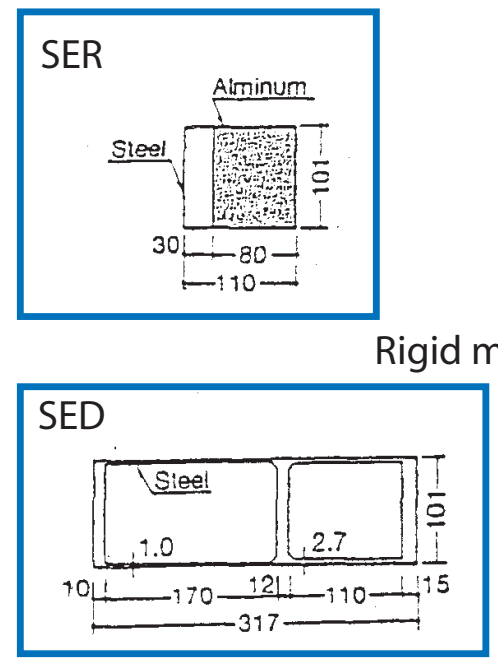

Deformable missiles
MER

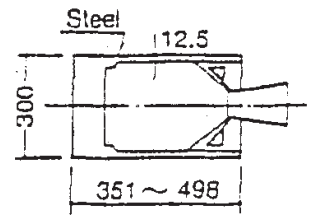

MED

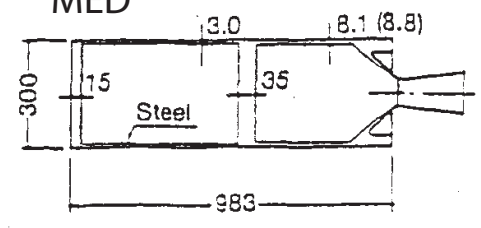

Deformable missiles
GE-J79
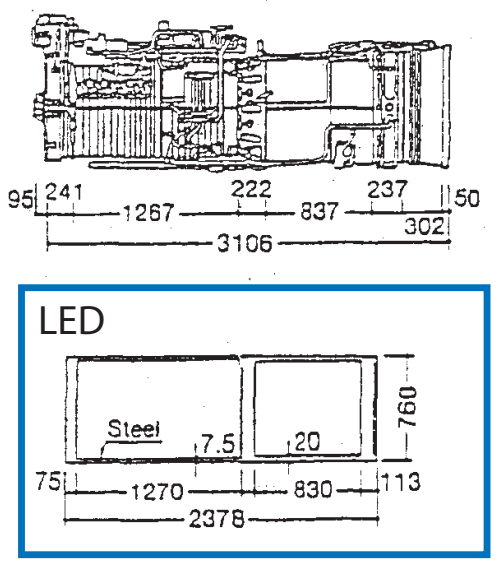

Deformable missiles

Fig. 18. The six different missiles used in Sandia tests
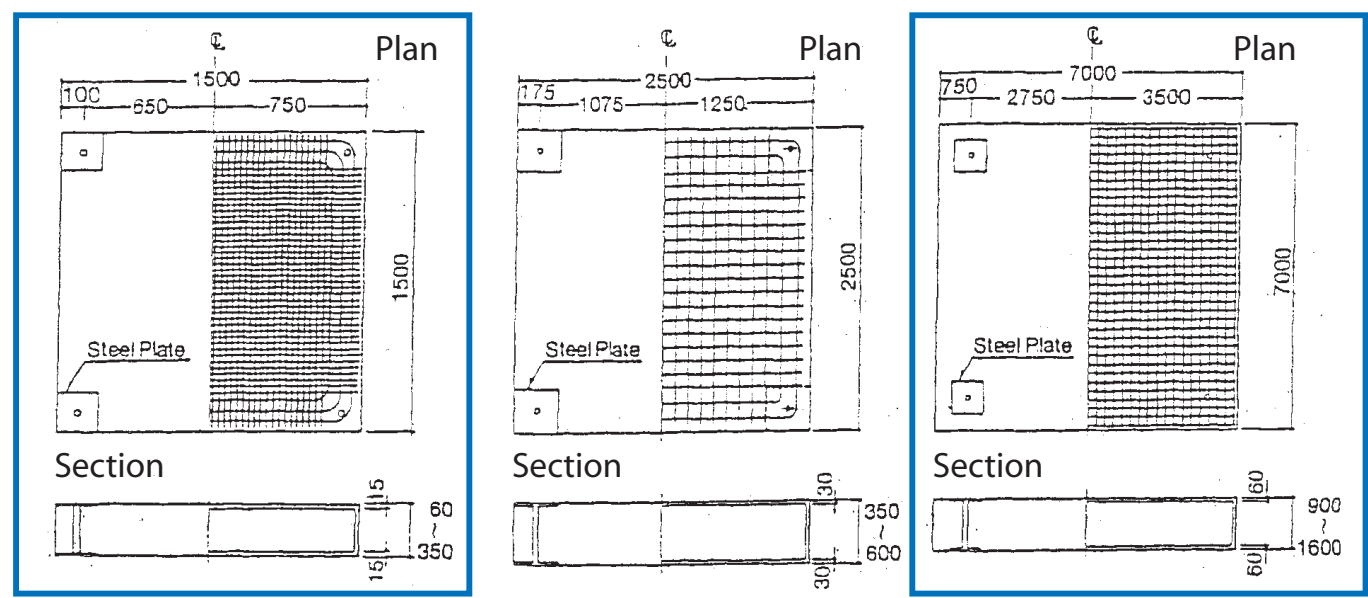

Fig. 19. The three different kind of impacted slabs in Sandia tests

Several illustrative numerical examples are presented in order to show a very satisfying performance of the proposed model. The most prominent is the example showing very good comparison with the experimental results obtained in Sandia's laboratory for impact problems on reinforced concrete slabs.

\section{References}

[1] Bigoni D. and Hueckel T., "Uniqueness and localization- I. Associative and non-associative elastoplasticity", Int. J. Solids and Structures, 28, 197-213 
(1991).

[2] Burlion N., Gatuingt F., Pijaudier-Cabot G. and Daudeville L., "Compaction and tensile damage in concrete: constitutive modelling and application to dynamics", Computer Methods in Applied Mechanics and Engineering, 183, 291-308 (2000).

[3] Burlion N., Pijaudier-Cabot G. and Dahan N., "Experimental analysis of compaction of concrete and mortar", Int. J. Numer. Anal. Meth. Geomech., 25, 1467-1486, 2001.

[4] Drucker DC and W. Prager, "Soil Mechanics and Plastic Analysis of Limit Design", Quart. Applied Mathematics, 10, 1952.

[5] Dube J.F., Pijaudier-Cabot G., and La Borderie C., "A Rate Dependent Damage Model for Concrete in Dynamics", J. of Engrg. Mech ASCE, 122, 939-947 (1996).

[6] François M., "MatSGen : user guide", Note interne du LMT-Cachan, (2004).

[7] Gatuingt F., "Prévision de la rupture des ouvrages en béton sollicités en dynamique rapide", Thèse de doctorat de l'ENS de Cachan, Cachan, France (1999).

[8] Gatuingt, F. and Pijaudier-Cabot, G., "Coupled damage and plasticity modelling in transient dynamic analysis of concrete", Int. J. Numer. Anal. Meth. Geomec.,26, 1-24, 2002.

[9] Gatuingt, F. and Pijaudier-Cabot, G., "Gurson's plasticity coupled to damage as a CAP Model for concrete compaction in dynamics", Constitutive Modelling of Geomaterials, CRC Press, 12-24, 2003.

[10] Gurson A. , "Continuum theory of Ductile Rupture by Void Nucleation and Growth: Part I - Yield Criteria and Flow Rules for Porous Ductile Media", J. Eng. Mater. Tech., 99, 2-15, 1977.

[11] Ibrahimbegovic A., D. Markovic, F. Gatuingt, "Constitutive model of coupled damage-plasticity and its finite element implementation", Eurpean J. Finite Elem., 12, 381-405, 2003.

[12] Hadamar J., "Lecons sur la Propagation des Ondes et les Equations de l'Hydrodynamique", Herman, Paris, 1903.

[13] Hallquist J.O., "LS-DYNA 3D -Theoretical Manual", Livermore Software Technology Corporation, Livermore, USA, (1995).

[14] Hill R., "Acceleration waves in solids", J. Mech. Phys. Solids, 10, 1-16, 1962.

[15] Klepaczko J.R. and Brara A., " An experimental method for dynamic tensile testing of concrete by spalling", International Journal of Impact Engineering, 25, 387-409, 2001.

[16] Mahnken R., "Aspects on the finite-element implementation of the Gurson model including parameter identification", International Journal of Plasticity, 15, 1111-1137, 1999.

[17] Needleman A. and Tvergaard V., "An analysis of ductile rupture in notched bars", Journal of Physics and mechanics of Solids, 32, 461-490 (1984). 
[18] Needleman A., "Material rate dependence and mesh sensitivity in localization problems", Computer Methods in Applied Mechanics and Engineering, 67, Issue 1, 69-85, 1988.

[19] Mazars J., "A description of micro and macroscale damage of concrete structures", Journal Engineering Fracture of Mechanics, 25, 729-737 (1986).

[20] Ortiz M. and Simo J.C., "An analysis of a new class of integration algoriths for elastoplastic constitutive relations", International Journal of Numerical Methods in Engineering, 23, 353-366, 1986.

[21] Rice J.R., "The localization of plastic deformation". In Theoretical and Applied Mechanics, North-Holland, Amsterdam, 1976.

[22] Rice J.R. and Rudnicki J.W., "A note on somes features of the theory of localization of deformations", Int. J. Solids Struct., 16, 597, 1980.

[23] Rudnicki J.W. and Rice J.R., "Conditions for the localization of deformations in pressure-sensitive dilatant materials", J. Mech. Phys. Solids, 23, 371, 1975.

[24] Sluys L.J., Wave Propagation, Localisation and Dispersion in Softening Solids, Doct. Dissertation, Delft University of Technology, The Netherlands, (1992).

[25] Sugano T., Tsubota H., Kasai Y., Koshika N., Ohnuma H., von Riensemann W.A., Bickel D.C. and Parks M.B., "Local damage to reinforced concrete structures caused by impact of aircraft engine missiles - Part 1 . Test program, method and results", Nuclear Engineering and Design, 140, 387-405 (1993).

[26] Sugano T., Tsubota H., Kasai Y., Koshika N., Ohnuma H., von Riensemann W.A., Bickel D.C. and Parks M.B., "Local damage to reinforced concrete structures caused by impact of aircraft engine missiles - Part 2 . Evaluation of test results", Nuclear Engineering and Design, 140, 407-423 (1993).

[27] Zienkiewicz O.C. and Taylor R.L., "The Finite Element Method - Volume 1 : The Basis", Butterworth and Heinemann, Elsevier Science (2000). 